Original Article Journal of Epilepsy Research pISSN 2233-6249 / elSSN 2233-6257

Received July 3, 2019

Revised September 28, 2019

Accepted January 9, 2020

Corresponding author:

Rajesh Kumar Goel, PhD

Department of Pharmaceutical Sciences and

Drug Research, Punjabi University,

Patiala-147002, Punjab 147002, India

Tel. +91-175-3046255

Fax. +91-175-2283073

E-mail; goelrkpup@gmail.com

\section{Modulatory Effect of Serotonergic System in Pentylenetetrazole-Induced Seizures and Associated Memory Deficit: Role of 5- $\mathrm{HT}_{1 \mathrm{~A}}$ and $5-\mathrm{HT}_{2 \mathrm{~A} / 2 \mathrm{C}}$}

\author{
Awanish Mishra, PhD ${ }^{1,2}$, Rajesh Kumar Goel, PhD ${ }^{1}$ \\ ${ }^{1}$ Department of Pharmaceutical Sciences and Drug Research, Punjabi University, Patiala; ${ }^{2}$ Department of \\ Pharmacology and Toxicology, National Institute of Pharmaceutical Education and Research-Raebareli (NIPER-R), \\ Lucknow, India
}

\begin{abstract}
Background and Purpose: Recent studies have recognised the memory deficit as one of the most common psychiatric issues in the patients with epilepsy, which severely affects the quality of life. Our previous studies have demonstrated the possible involvement of serotonergic system in the pathogenesis of epilepsy and associated memory deficit. The possible involvement of $5-\mathrm{HT}_{1 \mathrm{~A}}$ and $5-\mathrm{HT}_{2 \mathrm{~A} / 2 \mathrm{C}}$ receptor has not been explored yet. Therefore, this study has been envisaged to explore the effect of $5-\mathrm{HT}_{1 \mathrm{~A}}$ and $5-\mathrm{HT}_{2 \mathrm{~A} / 2 \mathrm{C}}$ receptor modulation on epilepsy and memory deficit in pentylenetetrazole-kindled mice.
\end{abstract}

Methods: In the present experimental approach, we examined the efficacy of modulation of 5- $\mathrm{HT}_{1 \mathrm{~A}}$ and $5-\mathrm{HT}_{2 \mathrm{~A} / 2 \mathrm{C}}$ receptor in pentylenetetrazole-induced kindling in male Swiss mice $(n=75)$. Mice were kindled by sub-convulsive dose of pentylenetetrazole ( $35 \mathrm{mg} / \mathrm{kg}$, intraperitoneal injection), at the interval of $48 \pm 2$ hours). Successfully kindled animals were treated with $5-\mathrm{HT}_{1 \mathrm{~A}}$ and $5-\mathrm{HT}_{2 \mathrm{~A} / 2 \mathrm{C}}$ receptor modulators. The effect of different treatments on seizure severity score and memory impairment was analysed.

Results: 5- $\mathrm{HT}_{1 \mathrm{~A}}$ receptor agonist improved the memory functions while seizure severity was not improved, and the opposite effect was observed with $5-\mathrm{HT}_{1 \mathrm{~A}}$ receptor antagonist. On the other hand, $5-\mathrm{HT}_{2 \mathrm{~A} / 2 \mathrm{C}}$ receptor agonist significantly improved memory deficit as well as seizure severity in the kindled animals.

Conclusions: The outcome of the study indicates the possible involvement of $5-\mathrm{HT}_{2 \mathrm{~A} / 2 \mathrm{C}}$ receptor in the pathogenesis of epilepsy and associated memory deficit, which can be further explored for its management. (2019;9:119-125)

Key words: Epilepsy, Memory disorders, Comorbidity, Pentylenetetrazole, Kindling, Serotonin, Receptor

\section{Introduction}

Recent studies have shown that there are growing concerns of cognitive problems in epileptic patients. ${ }^{1-3}$ The quality of life in the patients with epilepsy gets compromised with associated psychiatric conditions. Therefore, several studies have been carried out to understand the pathology and possible approaches management of memory deficit in epilepsy in past decades.

In our previous studies, we explored the possible involvement of serotonergic system in epilepsy and associated memory deficit. ${ }^{4-6}$ 5-HT receptors are involved not only in normal physiological function of brain like, sleep, memory, feeding and etc., but also in various psychiatric problems. The role of serotonergic innervations in epileptogenesis and consolidation of memory has been well documented. ${ }^{7}$
The differential effect of serotonergic system is corresponded by the virtue of their receptors. Because ofthe putative role of the serotonergic system in central physiological and pathological functions and the crucial need of identifying a novel target to prevent memory deficit in epilepsy, some serotonergic excitatory $\left(5-\mathrm{HT}_{2 \mathrm{~A} / 2 \mathrm{C}}\right)$ and inhibitory receptors $\left(5-\mathrm{HT}_{1 \mathrm{~A}}\right)$ were selected for the study.

$5-\mathrm{HT}_{1 \mathrm{~A}}$ receptor is predominantly distributed in limbic area and has been reported to exhibit antiepileptic effect. Differential effect of $5-\mathrm{HT}_{1 \mathrm{~A}}$ receptor agonist has been reported in epilepsy. $5-\mathrm{HT}_{1 \mathrm{~A}}$ receptor agonist has been reported to augment the latency to seizures in acute model of convulsions, while no effect has been observed in chronic amygdala kindling model. ${ }^{8}$ Typically, $5-\mathrm{HT}_{1 \mathrm{~A}}$ receptor antagonist has been reported to impair memory, whereas agonist has been found reverse memory deficit. ${ }^{9}$ In contrast, some studies suggest that 
5- $\mathrm{HT}_{1 \mathrm{~A}}$ receptor agonist may impair learning and memory in normal animals. $^{10}$

5- $\mathrm{HT}_{2 \mathrm{~A} / 2 \mathrm{C}}$ receptor appears to be widely expressed in cortex and hippocampus which regulates central nervous system excitability. ${ }^{11}$ Moreover, role of $5-\mathrm{HT}_{2 \mathrm{~A} / 2 \mathrm{C}}$ receptor has been implicated in various pathological conditions like epilepsy, depression, psychosis etc. A recent study has demonstrated the anticonvulsant effect of $5-\mathrm{HT}_{2 \mathrm{~A} / 2 \mathrm{C}}$ receptor agonist while presenting opposite effect with the antagonist. ${ }^{12}$ Activation of $5-\mathrm{HT}_{2 \mathrm{~A} / 2 \mathrm{C}}$ receptor has been mentioned to improve memory deficit.

However, there are only limited data available regarding the effect of $5-\mathrm{HT}_{1 \mathrm{~A}}$ and $5-\mathrm{HT}_{2 \mathrm{~A} / 2 \mathrm{C}}$ receptor in memory deficit in epilepsy. Converging evidence suggests that modulation of $5-\mathrm{HT}_{1 \mathrm{~A}}$ and 5-HT $\mathrm{H}_{2 \mathrm{~A} 2 \mathrm{C}}$ receptors might exhibit ameliorative effect on epilepsy and associated memory deficit. Therefore, this study was envisaged to explore the effect of $5-\mathrm{HT}_{1 \mathrm{~A}}$ and $5-\mathrm{HT}_{2 \mathrm{~A} / 2 \mathrm{C}}$ receptor ligands in pentylenetetrazole-kindling and associated memory deficit in mice.

\section{Methods}

\section{Chemicals}

Pentylenetetrazole, 8-OH-DPAT (5- $\mathrm{HT}_{1 \mathrm{~A}}$ receptor agonists), WAY-100,635 (5- $\mathrm{HT}_{1 \mathrm{~A}}$ receptor antagonists), $\mathrm{R}(-)$ DOI (5- $\mathrm{HT}_{2 \mathrm{~A}}$ receptor agonist) and other chemicals were procured from Sigma-Aldrich, Co. (St. Louis, MO, USA). Olanzapine (5-HT2A/2C receptor antagonist) was received as a gift sample form Q. P. Pharmachem, Derabassi, India.

\section{Animals}

The study was carried out on male Swiss mice (22-28 g weight), obtained from the approved breeder (Chaudhary Charan Singh Haryana Agricultural University, Hisar, Haryana, India). Animals were housed in standard cages at room temperature $\left(22^{\circ} \mathrm{C} \pm 2^{\circ} \mathrm{C}\right)$ under natural light/dark cycle, and the cage had free access to water and food (standard laboratory pellets). The animals were acclimatized to lab conditions for seven days before starting experiment. All the experimental work had been carried out from 8:00 am to 4:00 pm. The experimental protocol was duly approved by the Institutional Animal Ethics Committee (IAEC) and the care of the animals was carried out as per the guidelines of the Committee for the Purpose of Control and Supervision of Experiments on Animals (CPCSEA), Ministry of Environment and Forest, Government of India vide protocol approval No. 107/99/CPCSEA/-2009-4.2.

\section{Development of kindling}

Kindling in mice was induced by the method, which was previously validated in our laboratory. ${ }^{4-6,13,14}$ Briefly, pentylenetetrazole (dissolved in warm saline) was injected (sub-convulsive dose of $35 \mathrm{mg} / \mathrm{kg}$, intraperitoneal route, at $48 \pm 2$ hours interval) for 9 to 11 weeks until the animal shows appearance of tonic-clonic convulsion after two consecutive pentylenetetrazole administrations.

\section{Experimental protocol}

A total of 75 animals were employed in this study. The group I, naivve animals, consisted of untreated animals $(n=8)$ and rest of the animals were subjected to pentylenetetrazole (PTZ)-kindling.

Successfully kindled animals were randomly divided into seven groups: group II (vehicle control group) consisted of kindled animals receiving normal saline (10 mL/kg/day; i.p.; $\mathrm{n=8);} \mathrm{group} \mathrm{III} \mathrm{consisted}$ of kindled animals treated with 8-OH-DPAT (1 mg/kg/day; subcutaneous route [s.c.]; $n=7) ;^{15}$ group IV consisted of kindled animals receiving WAY-100,635 (0.3 mg/kg/day; s.c.; $n=8) ;{ }^{15}$ group V consisted of kindled animals receiving WAY-100,635+8-OH-DPAT $(n=7)$; group VI consisted of kindled animals receiving R (-) DOI (1 mg/kg/day; s.c.; $\mathrm{n}=7) ;{ }^{15}$ group VII consisted of kindled animals receiving olanzapine (2.5 mg/kg/day; S.c.; $\mathrm{n}=8){ }^{16}$ and group VIII consisted of kindled animals receiving olanzapine+ $R$ (-) DOI ( $n=7)$ (Fig. 1).

The above-mentioned treatment schedule was followed up to twenty days. Except naive ones, all kindled animals were challenged with additional pentylenetetrazole challenging dose (35 mg/kg; i.p.; just to mimic the clinical situation of occasional epileptic seizure) on a day $5,10,15$, and 20 of treatment schedule and the seizure severity score was recorded using a modified Racine's scale. ${ }^{4-6,13,14}$

\section{Behavioral assessments}

After 2 hours of pentylenetetrazole challenging dose, once their locomotor activity became normalized (as analysed by the open field test and actophotometer), animals were evaluated for their performance in the elevated plus maze and passive shock avoidance paradigm on day 20.

\section{Transfer latency in the elevated plus maze}

Spatial memory was evaluated recording transfer latency with the elevated plus maze on day 20, following the procedure previously standardized in our laboratory. ${ }^{4-6,13,14}$ 


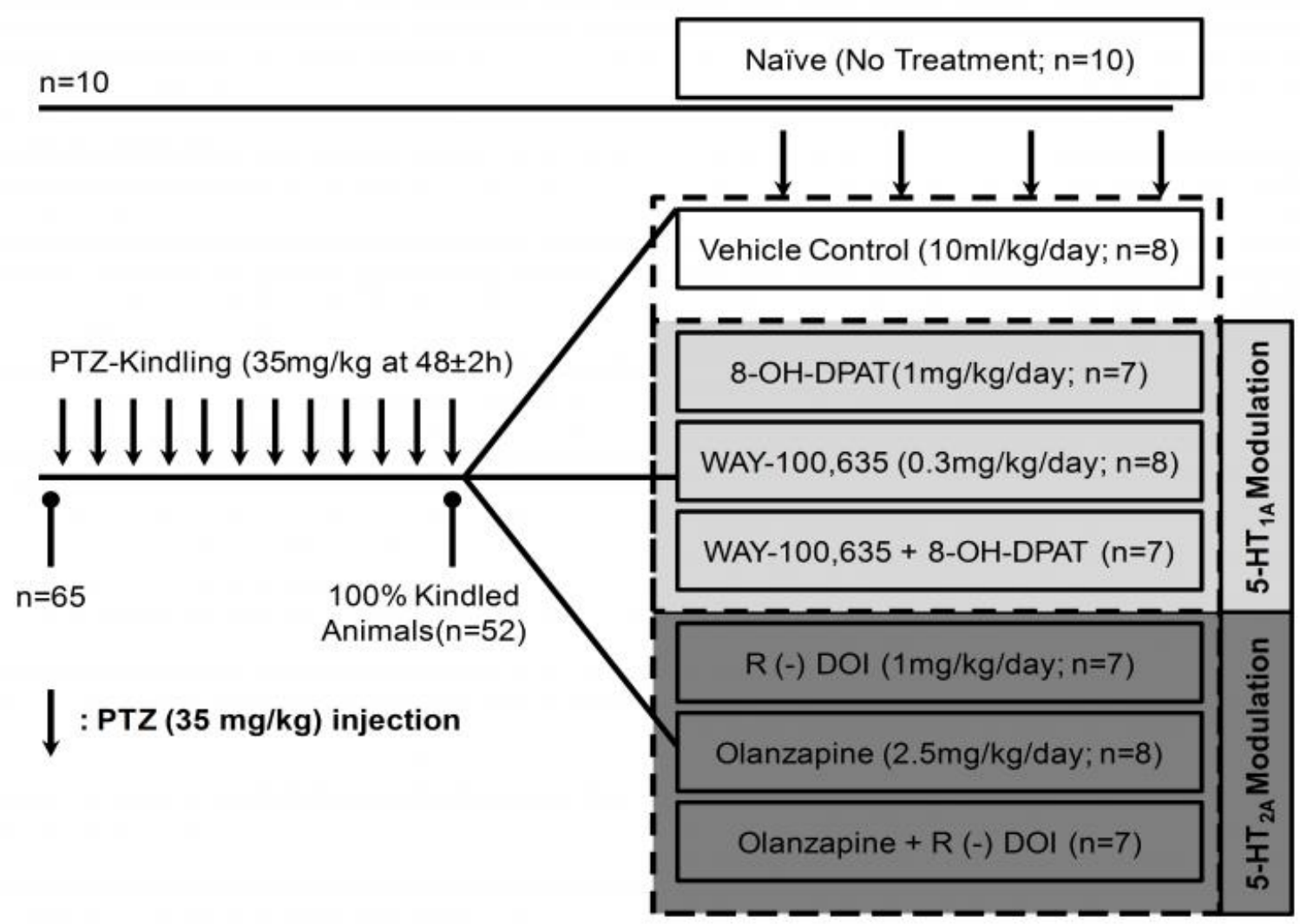

Figure 1. Schematic representation of experimental protocol. PTZ, pentylenetetrazole; 8-OH-DPAT, 5-HT 1 A receptor agonists; WAY100,635, 5-HT 1 A receptor antagonists; $\mathrm{R}$ (-) DOI, 5- $\mathrm{HT}_{2 \mathrm{~A}}$ receptor agonist; Olanzapine, 5- $\mathrm{HT}_{2 \mathrm{~A} / 2 \mathrm{C}}$ receptor antagonist.

Number of mistakes and step-down latency in passive shock avoidance paradigm

For the evaluation of contextual fear memory, the modified passive shock avoidance paradigm, which was previously standardized in our laboratory, was used. ${ }^{4-6,13,14}$ On day 0 animals were trained to stay on shock free zone for at least 120 seconds and the number of trials required were recorded. Further retrieval of a learned task was evaluated recording the changes in the number of mistakes andstepdown latency on day 20.

\section{Statistical analysis}

The statistical analysis was performed using the Sigma Stat Statistical software version 3.5 (Systat Software Inc., San Jose, CA, USA). Statistical significance in behavioural evaluations was calculated using one-way analysis of variance (ANOVA) followed by Tukey's test. Each value was expressed as mean \pm standard error of means (S.E.M.) and statistical significance was considered at $p<0.05$.

\section{Results}

Animals were considered kindled when they show tonic clonic seizures upon two consecutive PTZ injections. Around $13 \pm 3$ PTZ injections were administered to kindle the animals. Only successfully kindled animals ( $n=52)$ were included in the study, while animals showing mortality and resistance against PTZ kindling were excluded.

\section{Effect on seizure severity score}

There was a significant difference observed on seizure severity in different groups on day $20\left(F_{(7,52)}=32.930, p<0.001\right)$. Naïve animals did not receive PTZ challenging dose, therefore they did not shown convulsions. However, vehicle treated kindled animals have shown significant increase $(p<0.001)$ in the seizure severity, upon administration of PTZ challenging dose, as compared to naive animals. The treatment with 8-OH-DPAT did not change ( $p=0.271)$ the seizure severity score as compared to vehicle treated animals. However, the treatment with WAY-100,635 and WAY-100,635 in combination 
with 8-OH-DPAT significantly reduced $(p<0.001)$ the seizure severity score as compared to vehicle treated animals (Fig. 2A).

The treatment with DOI significantly reduced $(p<0.001)$ the seizure severity score as compared to vehicle treated animals. The treatment with olanzapine did not change $(p=1.000)$ the seizure severity score as compared to vehicle treated animals. The DOI and the olan- zapine combined treatment significantly reduced $(p<0.001)$ the seizure severity score as compared to vehicle treated animals (Fig. 2A).

\section{Effect on transfer latency}

The treatment with 8-OH-DPAT significantly reduced ( $p<0.001)$ transfer latency as compared to vehicle treated animals. The treat-

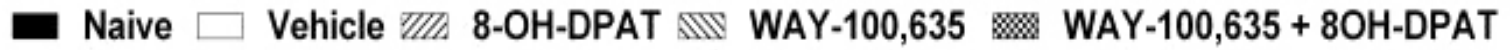 $\boxminus$ DOI $\quad$ III Olanzapine $\#$ Olanzapine + DOI}

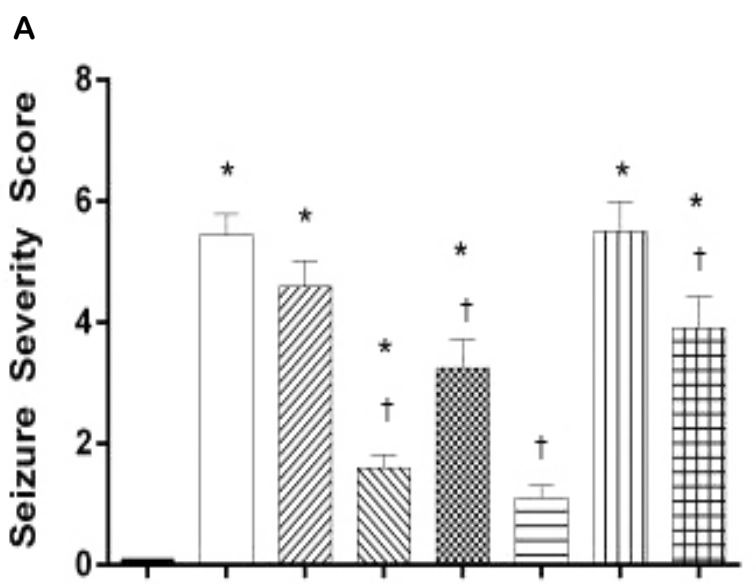

B

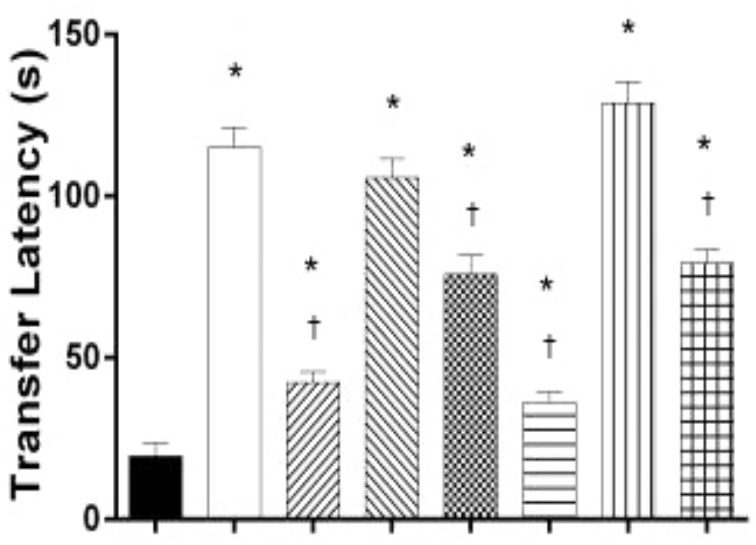

\section{Passive Shock Avoidance Test}

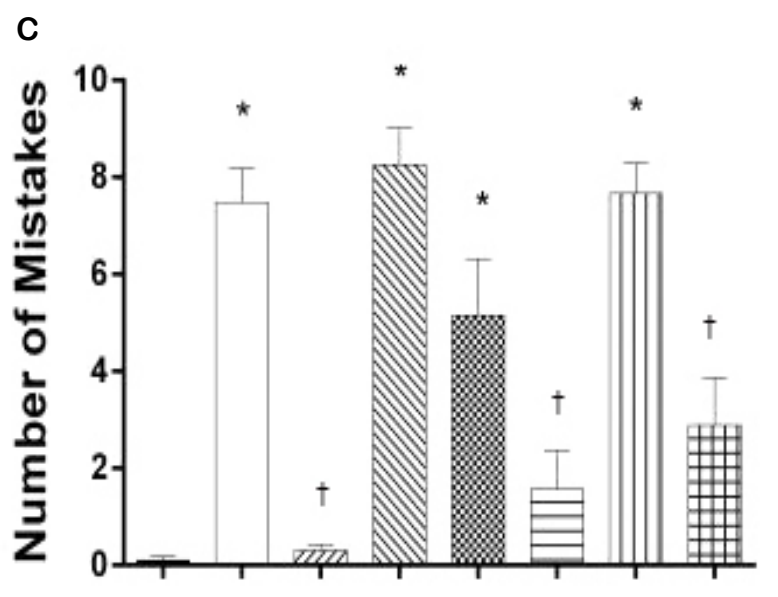

D

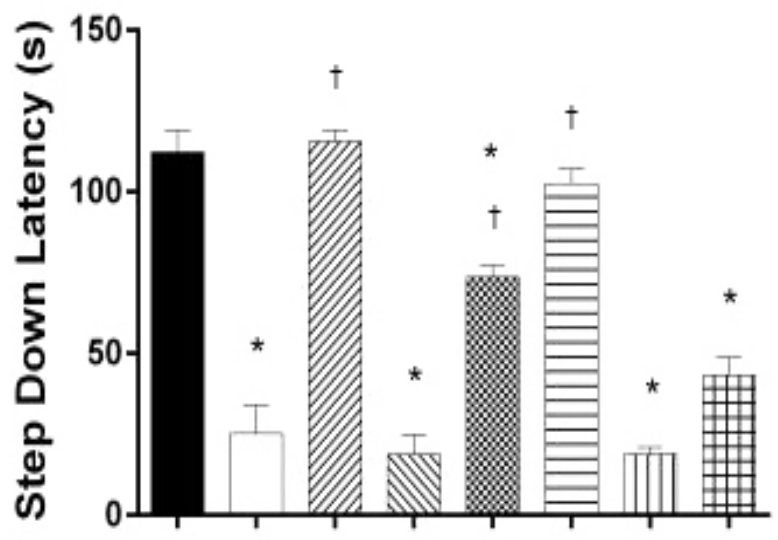

Figure 2. Effect of different treatments on behaviour of mice. On day 20 the behaviour of animal was recorded and effect of different treatments was recorded. (A) Effect on seizure severity score, (B) effect on transfer latency in elevated plus maze, (C) effect on number of mistakes in passive shock avoidance paradigm, and (D) effect on step down latency in passive shock avoidance paradigm. Each value is expressed as mean \pm standard error of means. The significance level was considered at $p<0.05$ (one way ANOVA followed by Tukey's test). 8-OH-DPAT, 5-HT 1A $_{\text {A }}$ receptor agonists; WAY100,635, 5-HT 1 A receptor antagonists; $\mathrm{R}(-) \mathrm{DOI}, 5-\mathrm{HT}_{2 \mathrm{~A}}$ receptor agonist; Olanzapine, $5-\mathrm{HT}_{2 \mathrm{~A} 2 \mathrm{C}}$ receptor antagonist. *As compared to naïve. ${ }^{\dagger}$ As compared to vehicle treated group. 
ment with WAY-100,635 did not change ( $p=0.087)$ transfer latency as compared to vehicle treated animals. However, the combined treatment of WAY-100,635 and 8-OH-DPAT significantly reduced transfer latency as compared to vehicle treated animals (Fig. 2B).

The treatment with $\mathrm{DOI}$ significantly reduced $(p<0.001)$ transfer latency as compared to vehicle treated animals. The treatment with olanzapine did not change $(p=0.117)$ transfer latency as compared to vehicle treated animals. The DOI and Olanzapine combined treatment significantly reduced $(p<0.001)$ transfer latency as compared to vehicle treated animals (Fig. 2B).

\section{Effect on number of mistakes and step-down latency}

The treatment with 8-OH-DPAT significantly reduced $(p<0.001)$ the number of mistakes and significantly increased $(p<0.001)$ step-down latency as compared to vehicle treated animals. However, the treatment with WAY-100,635 did not change number of mistakes $(p=0.471)$ and step-down latency $(p=0.404)$ as compared to vehicle treated animals. However combined treatment of WAY-100,635 and 8-OHDPAT significantly reduced the number of mistakes ( $p=0.002)$ and significantly increased step-down latency $(p<0.001)$ as compared to vehicle treated animals (Fig. 2C, D).

The treatment with DOI significantly reduced the number of mistakes $(p<0.001)$ and increased step-down latency $(p<0.001)$ as compared to vehicle treated animals. Treatment with olanzapine did not change the number of mistakes $(p=0.403)$ and the step-down latency $(p=0.680)$ as compared to vehicle treated animals. DOI and olanzapine combined treatment significantly reduced the number of mistakes $(p<0.001)$ and step-down latency $(p=0.035)$ as compared to vehicle treated animals (Fig. 2C, D).

\section{Discussion}

In this study, the treatment with 8-OH-DPAT (5-HT 1 A receptor agonist) did not change the elevated seizure severity score, suggesting no effect on convulsions in pentylenetetrazole-kindled animals. However, the WAY-100,635 (5-HT $1 \mathrm{~A}$ receptor antagonist) treatment was found to reduce the incidences of seizures in the pentylenetetrazole-kindled animals. High density of 5- $\mathrm{HT}_{1 \mathrm{~A}}$ receptors as somatodendritic autoreceptor and postsynaptic receptor has been reported to be found in hippocampus. ${ }^{17}$ The role of $5-\mathrm{HT}_{1 \mathrm{~A}}$ receptor in epilepsy appears intriguing as reports suggest their pro-convulsant ${ }^{18}$ and anticonvulsant ${ }^{8,19}$ potential in experimental models of convulsion. In our study treatment with 8-OH-DPAT did not improved seizure se- verity possibly due to reduction in hippocampal GABAergic tone. The inhibition of GABA release might be caused by stimulation of the $G$ protein-coupled presynaptic $5-\mathrm{HT}_{1 \mathrm{~A}}$ receptors mediated inactivation of the adenylyl cyclase/cAMP signal transduction pathway. ${ }^{20}$ This might be a speculation for negligible effect of $5-\mathrm{HT}_{1 \mathrm{~A}}$ receptor agonist and anticonvulsant effect of $5-\mathrm{HT}_{1 \mathrm{~A}}$ receptor antagonist.

8-OH-DPAT has also been reported to bind with $5-\mathrm{HT}_{7}$ receptor. ${ }^{21}$ Therefore the possible interaction of 8-OH-DPAT with $5-\mathrm{HT}_{7}$ receptor in this study cannot be neglected. The activation of $5-\mathrm{HT}_{7}$ receptor by selective agonist has been reported to increase seizures in pilocarpine induced rat model of temporal lobe epilepsy. ${ }^{22}$ In contrast, antagonism of $5-\mathrm{HT}_{7}$ receptor has been reported to reduce spontaneous seizures in the WAG/Rij rat model of absence epilepsy ${ }^{19}$ and pilocarpine induced spontaneous seizures. ${ }^{22}$ Therefore activation of 5- $\mathrm{HT}_{7}$ receptor might be another hypothesis in support of negligible/proconvulsant nature of 8-OH-DPAT in our study. Generally, depletion of 5-HT level has been found to be associated with reduced seizures threshold ${ }^{23}$ while agents which elevate extracellular serotonin level have been found to have anticonvulsant effect. ${ }^{24}$ WAY-100,635 has been reported to increase extracellular 5-HT lev$\mathrm{el}^{25}$ and might suggest another hypothesis for its anticonvulsant effect of WAY-100,635 and opposite/negligible effect of 8-OH-DPAT, in our study.

Behavioural findings of this study suggested that the 8-OH-DPAT treatment improves memory function by reducing transfer latency in elevated plus maze and by increasing step-down latency in the passive shock avoidance paradigm. However, the WAY-100,635 treatment impaired memory in the pentylenetetrazole-kindled animals, as observed by increased transfer latency and reduced step-down latency. The protective effect of the 8-OH-DPAT treatment was significantly reversed by co-administration of WAY-100,635 in this study. Systemically administered $5-\mathrm{HT}_{1 \mathrm{~A}}$ receptor agonists, either by inhibitory somadendritic $5-\mathrm{HT}_{1 \mathrm{~A}}$ autoreceptor or by the inhibitory 5-HT ${ }_{1 A}$ receptor on GABAergic interneurons, might be involved in the indirect facilitation of acetylcholine (ACh) release in hippocampus, and thus helps in improvement in memory. ${ }^{26}$ However, $5-\mathrm{HT}_{1 \mathrm{~A}}$ receptor antagonist might result in depletion of hippcampal ACh level, and thus producing memory deficit in the pentylenetetrazole-kindled animals. The protective effect of 8-OH-DPAT on memory can also be supported by another hypothesis which includes stimulation of $5-\mathrm{HT}_{7}$ receptor and the stimulation has been documented to improve hippocampal based cognitive process. ${ }^{27}$

The treatment with DOI (5- $\mathrm{HT}_{2 \mathrm{~A} / 2 \mathrm{C}}$ receptor agonist) has shown 
anticonvulsant potential in the pentylenetetrazole-kindled animals. However, this anticonvulsant effect was antagonized by Olanzapine (5- $\mathrm{HT}_{2 \mathrm{~A} / 2 \mathrm{c}}$ receptor antagonist) pre-treatment. Activation of $5-\mathrm{HT}_{2}$ receptors in hippocampal region causes release of $\mathrm{GABA}^{28}$ which might support anticonvulsant effect of DOI treatment and no protective effect with Olanzapine treatment, in our study. The treatment with $5-\mathrm{HT}_{2}$ receptor agonist has also been reported to inhibit glutamate release (via inhibitory presynaptic receptors) from cerebellar mossy fibre terminals, ${ }^{29}$ which could be speculated as another possible anticonvulsant mechanism of $5-\mathrm{HT}_{2}$ receptor agonist. Olanzapine has been reported to have proconvulsant nature ${ }^{30}$ which might be attributed due to their antagonistic effect on dopaminergic D2 receptor. $^{31}$

Behavioural evaluation suggested that DOI treatment significantly improved memory by reducing transfer latency in elevated plus maze and by increasing step-down latency in passive shock avoidance paradigm. The opposite effect was observed with Olanzapine treatment. Activation of $5-\mathrm{HT}_{2 \mathrm{~A} / 2 \mathrm{C}}$ receptor has long been reported to improve memory functions ${ }^{32}$ possibly via enhancingglutamate and acetylcholine release in prefrontal cortex and hippocampus. ${ }^{33,34}$ These can be speculated as possible mechanisms for the memory improvement effect in DOI treated animals and vice-versa in Olanzapine treated animals.

In conclusion, this study demonstrates the protective effect of $5-\mathrm{HT}_{2 \mathrm{~A} / 2 \mathrm{C}}$ receptor agonist on seizure severity and associated memory deficit in pentylenetetrazole-kindled animals. On the other hand, modulation of $5-\mathrm{HT}_{1 \mathrm{~A}}$ resulted in improving either seizures or memory impairment in animals. Furthermore, findings of this study may also suggest possible involvement of $5-\mathrm{HT}_{2 \mathrm{~A} / 2 \mathrm{C}}$ receptor in the development and management of epilepsy associated memory deficit. However, therapeutic application of 5- $\mathrm{HT}_{2 \mathrm{~A} / 2 \mathrm{C}}$ receptor hypothesis for the management of epilepsy associated memory deficit warrants further studies to confirm its other psychiatric effects.

\section{Acknowledgements}

The authors would like to acknowledge the Indian Council of Medical Research, New Delhi, India for funding of this research work (Grant No. 45/33/2010/PHA-BMS).

\section{Conflicts of Interest}

The authors declare that they have no conflict of interest.

\section{References}

1. Kambaja B, Dupont S. Amnesia, memory disturbances and epilepsy. Geriatr Psychol Neuropsychiatr Vieil 2016;14:415-9.

2. Sekimoto $M$, Muramatsu $R$, Kato $M$, Onuma T. Clinical and neuropsychological changes after the disappearance of seizures in a case of transient epileptic amnesia. Epilepsy Behav Case Rep 2017;7:54-7.

3. Prada Jardim A, Liu J, Baber J, et al. Characterising subtypes of hippocampal sclerosis and reorganization: correlation with pre and postoperative memory deficit. Brain Pathol 2018;28:143-54.

4. Mishra A, Goel RK. Age dependent learning and memory deficit in Pentylenetetrazol kindled mice. Eur J Pharmacol 2012;674:315-20.

5. Mishra A, Goel RK. Psychoneurochemical investigations to reveal neurobiology of memory deficit in epilepsy. Neurochem Res 2013;38:2503-15.

6. Mishra A, Goel RK. Chronic 5-HT3 receptor antagonism ameliorates seizures and associated memory deficit in pentylenetetrazole-kindled mice. Neuroscience 2016;17:319-28.

7. Bagdy G, Kecskemeti V, Riba P, Jakus R. Serotonin and epilepsy. J Neurochem 2007;100:857-73.

8. López-Meraz ML, González-Trujano ME, Neri-Bazán L, Hong E, Rocha LL. 5-HT1A receptor agonists modify epileptic seizures in three experimental models in rats. Neuropharmacology 2005;49:367-75.

9. Micheau J, Van Marrewijk B. Stimulation of 5-HT1A receptors by systemic or medial septum injection induces anxiogenic-like effects and facilitates acquisition of a spatial discrimination task in mice. Prog Neuropsychopharmacol Biol Psychiatry 1999;23:1113-33.

10. Egashira N, Yano A, Ishigami N, et al. Investigation of mechanisms mediating 8-OH-DPAT-induced impairment of spatial memory: involvement of 5-HT1A receptors in the dorsal hippocampus in rats. Brain Res 2006; 1069:54-62.

11. Xu T, Pandey SC. Cellular localization of serotonin(2A) (5HT(2A)) receptors in the rat brain. Brain Res Bull 2000;51:499-505.

12. Hidaka N, Suemaru K, Araki H. Serotonin-dopamine antagonism ameliorates impairments of spontaneous alternation and locomotor hyperactivity induced by repeated electroconvulsive seizures in rats. Epilepsy Res 2010;90:221-7.

13. Mishra A, Goel RK. Adjuvant anticholinesterase therapy for the management of epilepsy-induced memory deficit: a critical pre-clinical study. Basic Clin Pharmacol Toxicol 2014;115:512-7.

14. Mishra A, Goel RK. Comparative behavioral and neurochemical analysis of phenytoin and valproate treatment on epilepsy induced learning and memory deficit: search for add on therapy. Metab Brain Dis 2015; 30:951-8.

15. Kaster MP, Santos AR, Rodrigues AL. Involvement of 5-HT1A receptors in the antidepressant-like effect of adenosine in the mouse forced swimming test. Brain Res Bull 2005;67:53-61.

16. Choi S, DiSilvio B, Unangst J, Fernstrom JD. Effect of chronic infusion of olanzapine and clozapine on food intake and body weight gain in male and female rats. Life Sci 2007;81:1024-30. 
17. Muchimapura S, Mason R, Marsden CA. Effect of isolation rearing on pre- and postsynapticserotonergic function in the rat dorsal hippocampus. Synapse 2003;47:209-17.

18. Gerber K, Filakovszky J, Halasz P, Bagdy G. The 5-HT1A agonist 8-OH-DPAT increases the number of spike-wave discharges in a genetic rat model of absence epilepsy. Brain Res 1998;807:243-5.

19. Graf M, Jakus R, Kantor S, Levay F, Bagdy G. Selective 5-HT1A and 5-HT7 antagonists decrease epileptic activity in the WAG/Rij rat model of absence epilepsy. Neurosci Lett 2004;359:45-8.

20. Hannon J, Hoyer D. Molecular biology of 5-HT receptors. Behav Brain Res 2008;195:198-213.

21. Hedlund PB, Kelly L, Mazur V, Lovenberg T, Sutcliffe JG, Bonaventure P. 8-OH-DPAT acts on both 5-HT1A and 5-HT7 receptors to induce hypothermia in rodents. Eur J Pharmacol 2004;487:125-32.

22. Yang $Z$, Liu $X$, Yin $Y$, Sun S, Deng $X$. Involvement of 5-HT7 receptors in the pathogenesis of temporal lobe epilepsy. Eur J Pharmacol 2012; 685:52-8.

23. Mazarati AM, Baldwin RA, Shinmei S, Sankar R. In vivo interaction between serotonin and galanin receptors types 1 and 2 in the dorsal raphe: implication for limbic seizures. J Neurochem 2005;95:1495-503.

24. Kecskeméti V, Rusznák Z, Riba P, et al. Norfluoxetine and fluoxetine have similar anticonvulsant and $\mathrm{Ca} 2+$ channel blocking potencies. Brain Res Bull 2005;67:126-32.

25. Dreshfield-Ahmad $\sqcup$, Thompson DC, Schaus JM, Wong DT. Enhancement in extracellular serotonin levels by 5-hydroxytryptophan loading after administration of WAY 100635 and fluoxetine. Life Sci 2000;66:2035-41.

26. Lüttgen $M$, Elvander $E$, Madjid N, Ogren SO. Analysis of the role of
5-HT1Areceptors in spatial and aversive learning in the rat. Neuropharmacology 2005;48:830-52.

27. Eriksson TM, Golkar A, Ekström JC, Svenningsson P, Ogren SO. 5-HT7 receptor stimulation by 8-OH-DPAT counteracts the impairing effect of 5-HT(1A) receptor stimulation on contextual learning in mice. Eur $J$ Pharmacol 2008:596:107-10.

28. Shen RY, Andrade R. 5-Hydroxytryptamine2 receptor facilitates GABAergic neurotransmission in rat hippocampus. J Pharmacol Exp Ther 1998:285:805-12.

29. Maura G, Carbone R, Guido M, Pestarino M, Raiteri M. 5-HT2 presynaptic receptorsmediate inhibition of glutamate release from cerebellar mossy fibre terminals. Eur J Pharmacol 1991;202:185-90.

30. Behere RV, Anjith D, Rao NP, Venkatasubramanian G, Gangadhar BN. Olanzapine-induced clinical seizure: a case report. Clin Neuropharmacol 2009:32:297-8.

31. Torta R, Monaco F. Atypical antipsychotics and serotoninergic antidepressants in patients with epilepsy: pharmacodynamic considerations. Epilepsia 2002;43:8-13.

32. Williams GV, Rao SG, Goldman-Rakic PS. The physiological role of 5-HT2A receptors in working memory. J Neurosci 2002;22:2843-54.

33. Scruggs $J L$, Patel $S$, Bubser $M$, Deutch AY. DOI-Induced activation of the cortex: dependence on 5-HT2A heteroceptors on thalamocortical glutamatergicneurons. J Neurosci 2000;20:8846-52.

34. Nair SG, Gudelsky GA. Activation of 5-HT2 receptors enhances the release ofacetylcholine in the prefrontal cortex and hippocampus of the rat. Synapse 2004;53:202-7. 